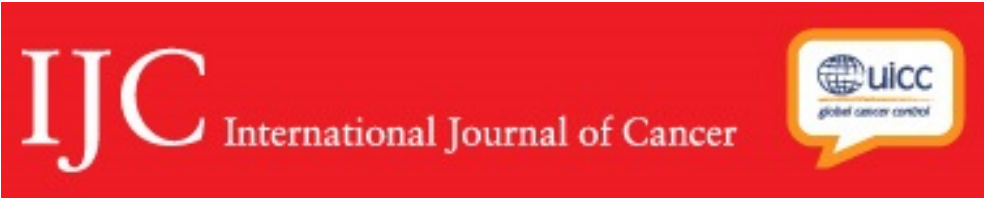

\title{
Adefovir dipivoxil induces DNA replication stress and augments ATR inhibitor related cytotoxicity
}

\begin{tabular}{|r|l|}
\hline Journal: & International Journal of Cancer \\
\hline Manuscript ID & IJC-19-2201.R2 \\
\hline Wiley - Manuscript type: & Research Article \\
\hline Author: & n/a \\
\hline Complete List of Authors: & $\begin{array}{l}\text { Patel, Agata; Gray Institute for Radiation Oncology and Biology, The } \\
\text { Department of Oncology } \\
\text { Seraia, Elena; Oxford University, Target Discovery Institute, The Nuffield } \\
\text { Department of Medicine } \\
\text { Ebner, Daniel; Oxford University, Target Discovery Institute, The Nuffield } \\
\text { Department of Medicine } \\
\text { Ryan, Anderson; Gray Institute for Radiation Oncology and Biology, } \\
\text { Oncology }\end{array}$ \\
\hline Key Words: & $\begin{array}{l}\text { DNA replication stress, replication catastrophe, ATR inhibitor, adefovir } \\
\text { dipivoxil, pan-nuclear yH2AX, DNA damage, non-replicating S-phase, } \\
\text { chemotherapy, drug screen }\end{array}$ \\
\hline
\end{tabular}

\section{SCHOLARONE"}

Manuscripts 


\title{
Adefovir dipivoxil induces DNA replication stress and augments ATR inhibitor related cytotoxicity
}

\author{
Agata Patel $^{1 *}$, Elena Seraia ${ }^{2}$, Daniel Ebner ${ }^{2}$, Anderson Joseph Ryan ${ }^{1}$ \\ 1. Oxford Institute for Radiation Oncology, The Department of Oncology, University of \\ Oxford, OX3 7DQ, Oxford, UK \\ 2. Target Discovery Institute, The Nuffield Department of Medicine, University of \\ Oxford, OX3 7DQ, Oxford, UK
}

Key words: adefovir dipivoxil, DNA replication stress, replication catastrophe, ATR inhibitor, pan-nuclear $\gamma \mathrm{H} 2 \mathrm{AX}$

Abbreviations: ATM: Ataxia Telangiectasia Mutated; ATR: Ataxia Telangiectasia Mutated (ATM) and Rad3 related, ATRi: ATR inhibitor; ATRIP: ATR-interacting protein; BRCA2: breast cancer type 2; BrdU: bromodeoxyuridine; CHK1: checkpoint kinase 1; CDK2: cyclin dependent kinase 2; dNTP: deoxynucleotide triphosphate; DSBs: DNA double-strand breaks; DDR: DNA damage repair; EdU: 5-Ethynyl-2'-deoxyuridine; HR: homologous recombination; HU: hydroxyurea; RPA: replication protein A; RRM2: ribonucleotide reductase M2; ssDNA: single-stranded DNA

*Corresponding author at: Department of Oncology, Oxford Institute for Radiation Oncology, University of Oxford, Roosevelt Drive, Headington, Oxford OX3 7DQ, UK.

Tel.: +44 186517353. E-mail address: agata.patel@oncology.ox.ac.uk (A.Patel). 


\begin{abstract}
Replication stress is a common feature of cancer cells. Ataxia Telangiectasia Mutated (ATM) and $\operatorname{Rad} 3$ related (ATR) signalling, a DNA damage repair (DDR) pathway, is activated by regions of single-stranded DNA (ssDNA) that can arise during replication stress. ATR delays cell cycle progression and prevents DNA replication fork collapse, which prohibits cell death and promotes proliferation. Several ATR inhibitors have been developed in order to restrain this protective mechanism in tumours. It is known, however, that despite other effective anticancer chemotherapy treatments targeting DDR pathways, resistance occurs. This begets the need to identify combination treatments to overcome resistance and prevent tumour cell growth. We conducted a drug screen to identify potential synergistic combination treatments by screening an ATR inhibitor (VE822) together with compounds from a bioactive small molecule library. The screen identified adefovir dipivoxil, a reverse transcriptase inhibitor and nucleoside analogue, as a compound that has increased cytotoxicity in the presence of ATR, but not ATM or DNA-PK inhibition.

Here we demonstrate that adefovir dipivoxil induces DNA replication stress, activates ATR signalling and stalls cells in $\mathrm{S}$ phase. This simultaneous induction of replication stress and inhibition of ATR signalling, leads to a marked increase in pan-nuclear $\gamma \mathrm{H} 2 \mathrm{AX}$ positive cells, ssDNA accumulation, and cell death, indicative of replication catastrophe.
\end{abstract}

\title{
Novelty and impact
}

Replication stress is a common feature of cancer cells, making them susceptible to ATR inhibition. Our data is the first to reveal that adefovir dipivoxil, a reverse transcriptase inhibitor, induces DNA replication stress in cancer, and raises its potential to be a new approach to enhance cytotoxicity of ATR inhibition in tumour cells. This data adds to growing evidence that targeting cells under high DNA replication stress can increase cancer cell killing by ATR inhibition. 


\section{Introduction}

Eukaryotic genomes are exposed to mild forms of naturally occurring replication stress during cell cycle ${ }^{1}$. Pathological settings, however, such as activation of oncogenes, can increase the level of replication stress, leading to DNA damage and genomic instability ${ }^{2}$. As a result, maintaining the stability of genomic DNA is crucial for the survival of any cell, including cancer cells. Cells have therefore developed mechanisms to protect their DNA, such as Ataxia Telangiectasia Mutated (ATM) and Rad3 related (ATR) signalling, one of the DNA damage repair (DDR) pathways 3, 4. Upon replication stress, ATR signalling stabilises stalled replication forks, counteracts new origin firing and delays cell cycle progression 5, 6

It has been shown that persistent replication stress results in conversion of stalled replication forks to 'collapsed forks' 7, 8, which can lead on to DNA double-strand breaks (DSBs), considered the most critical DNA lesions ${ }^{9}$. ATR signalling is known to delay the onset of fork collapse ${ }^{10}$ and replication catastrophe, a fragmentation of replicating chromosomes ${ }^{11,12}$. This response takes many hours to develop ${ }^{13}$, and has been reported to occur due to accumulation of ribonucleotide reductase M2 (RRM2) and reduction in origin firing in S phase ${ }^{14}$.

Due to replication stress being a common feature of cancer cells ${ }^{1}$, a property that makes them susceptible to ATR inhibition, several inhibitors have been developed in order to restrain this protective mechanism. VE822 (also known as VX-970 or berzosertib) is the first selective ATR inhibitor (ATRi) to enter clinical trials. VE822 significantly sensitised a panel of tumour cell lines, but not normal cells, to DNA damaging drugs, including cisplatin, gemcitabine, and irinotecan ${ }^{15,16}$. The tolerability and pharmacokinetics of VE822 in combination with cytotoxic chemotherapy are currently being assessed in a phase I clinical trial (ClinicalTrials.gov: NCT02157792). Based on other anti-cancer therapies targeting DDR pathways, it is known that, despite initially positive results, most cancers eventually develop resistance to therapies ${ }^{17-}$ ${ }^{20}$. This begets the need to identify combination treatments to prevent the emergence of drug resistance and to provide sustained inhibition of tumour cell growth ${ }^{21}$.

It has been shown that the checkpoint kinase 1 (CHK-1, known as the ATR effector kinase) pathway, can function independently of ATR and allow cells to tolerate moderate replication stress during ATR inhibition ${ }^{14}$. We hypothesized that inhibition of the ATR pathway in the presence of higher levels of DNA replication stress, would more effectively kill cancer cells. We conducted a drug screen aiming to identify potential combination therapies by screening an ATRi (VE822), together with a bioactive small molecule library that included targeted therapies as well as standard chemotherapy agents.

Our drug screen revealed adefovir dipivoxil, a nucleoside analogue and reverse transcriptase inhibitor ${ }^{22-24}$, that induces replication stress and leads to enhanced cytotoxicity with ATR inhibition, which may have clinical implications. 


\section{Material and Methods}

Drugs and chemicals:

Adefovir dipivoxil, adefovir, cidofovir, docetaxel (Stratech Scientific Ltd), HU and gemcitabine (Sigma-Aldrich), were used as indicated in Figure legends. Inhibitors for ATM (KU55933), ATR (VE822, VE821), and DNA-PKcs (NU7441) (Stratech Scientific Ltd), were applied as indicated. Deoxynucleotide triphosphate (dNTP) analogues: bromodeoxyuridine (BrdU, Sigma-Aldrich) and 5-ethynyl-2'-deoxyuridine (EdU, Thermo Fisher Scientific) were used as indicated. Bovine serum albumin (BSA), Triton X-100, sodium tetraborate and Tween20 (Sigma-Aldrich), normal goat serum (Merck Millipore), Hoechst (Thermo Fisher Scientific), propidium iodide (PI, Sigma-Aldrich) and RNaseA (Sigma-Aldrich), were used as indicated.

\section{Cell culture}

H1975 [CVCL_1511], A549 [CVCL_0023], were obtained from American Type Culture Collection; (ATCC, Queens Road, Teddington, UK). PC-9 cells [CVCL_B260] were a kind gift from Dr Kazuto Nishio (Kinki University, Japan) ${ }^{25}$. DLD1 [CVCL_0248], as well as DLD1 BRCA2(-/-) [CVCL_HD57] were obtained from Horizon Discovery (8100 Cambridge Research Park, UK). NBE1 cells [CVCL_9Y83] were a kind gift from Dr Pamela Rabbitts (University of Leeds, UK). All cell lines have been authenticated using Short Tandem Repeat (STR) profiling within the last three years. All experiments were performed with mycoplasmafree cells ${ }^{26}$.

Cell were routinely passaged in advanced DMEM (Thermo Fisher Scientific) supplemented with $5 \%$ fetal bovine serum (FBS, Sigma-Aldrich), 1\% Glutamax (Thermo Fisher Scientific) and $1 \%$ Pen/Strep (Thermo Fisher Scientific).

\section{Drug screen}

Due to the number of compounds in the screen (1902 compounds +/- VE822) we took a pragmatic approach and chose two drug concentrations: 0.1 and $1 \mu \mathrm{M}$. However, there are limitations to using this approach, compounds with a very high $(\mathrm{IC} 50<<0.1 \mu \mathrm{M})$, or low potency (IC50 $>>1 \mu \mathrm{M})$ may not be detected.

H1975 human non-small cell lung cancer adenocarcinoma cells were plated (300 cells/well) into 384 well plates using a Janus automatic liquid handler. $18 \mathrm{~h}$ later bioactive compounds ( $\mathrm{n}=1902,0.1$ and $1 \mu \mathrm{M}, \mathrm{L} 1700$ library Selleck Chemicals) were added alone or in combination with VE822 $(0.1 \mu \mathrm{M})$ using an Echo 555 liquid handler. On day 6 after treatment relative cell proliferation, either to DMSO (for treatments with bioactive compounds alone), or to VE822 (for treatments with bioactive compounds and VE822), was measured $2 \mathrm{~h}$ after addition of resazurin $(12.5 \mu \mathrm{g} / \mathrm{ml}$, Sigma-Aldrich; excitation $544 \mathrm{~nm}$, emission $590 \mathrm{~nm})$. Z-scores were calculated as an average of $\log 10$ relative proliferation ([compounds alone]/[compounds+VE822]). Cell proliferation in the presence of ATR inhibition alone was between $70-90 \%$ of DMSO control. The reproducibility $\left(\mathrm{R}^{2}\right)$ between replicates was in a 0.8 0.9 range.

\section{Proliferation and clonogenic assay}

For the resazurin proliferation assay, cells were plated (H1975: 700; A549: 500; PC9: 300; DLD1: $\mathrm{BRAC2}^{+/+} 600$; DLD1: $\mathrm{BRAC2} 2^{-/-} 800$ cells/well) in at least triplicate, into 96 well 
plates. $18 \mathrm{~h}$ later bioactive compounds (adefovir dipivoxil, adefovir, cidofovir) were added alone or in combination with VE822, KU55933 or NU7441 inhibitor. On day 6 relative cell proliferation was measured, as described above.

For clonogenic survival assay H1975 cells were platted in triplicate into 6 well plates at the concentration: 200, 500 or 1000 cells/well, depending on the treatment. Cells were left to attach for $16 \mathrm{~h}$, then were treated with adefovir dipivoxil alone or in combination with VE822. Cells were washed with PBS and medium was exchanged for drug-free medium at 2, 24 or $144 \mathrm{~h}$ and colonies were left to grow. After 2 weeks, when the size of colonies was $\geq 50$ cells, they were stained with crystal violet and counted. Data were calculated as relative survival fraction to DMSO control.

\section{Immunoblotting and antibodies used:}

Whole-cell extracts (WCE), obtained by using lysis buffer (50 mM Tris-HCl [pH 7.6], $137 \mathrm{mM}$ $\mathrm{NaCl}, 0.1 \%$ Igepal, $0.1 \%$ SDS, $10 \%$ glycerol, $50 \mathrm{mM} \mathrm{NaF}$ ), supplemented with $1 \mathrm{x}$ protease and $1 \mathrm{mM} \mathrm{Na} \mathrm{VO}_{4}$ phosphatase inhibitors (Sigma-Aldrich) before use, were analyzed by SDSPAGE following standard procedures. The membranes were either scanned by the Odyssey ${ }^{\circledR} \mathrm{Sa}$ Infrared Imaging System (LI-COR) or developed using Bio-Rad developing solution in conjunction with X-ray film (relevant for Cyclin F and E2F1).

Antibodies: $\gamma \mathrm{H} 2 \mathrm{AX}$ pSer139 monoclonal antibody (1:1000, clone JBW301, 05-636 EMD Millipore), RPA32 pSer4/Ser8 polyclonal antibody (1:1000, A300-245A, Bethyl Laboratories), CHK1 pS317 polyclonal antibody (1:1000, 2344, Cell Signaling Technology), CHK2 pT68 polyclonal antibody (1:1000, 2661, Cell Signaling Technology), ATM pSer1981 monoclonal antibody $(1: 10000$, clone EP1890Y, ab81292, Abcam), KAP-1 pSer824 polyclonal antibody (1:2000, A300-767A, Bethyl Laboratories), PARP polyclonal antibody (1:2000, 9542, Cell Signaling Technology), Cyclin F polyclonal antibody (1:5000, A303406A, Bethyl Laboratories), Cyclin A monoclonal antibody (1:500, clone 6E6, ab16726, Abcam), E2F1 monoclonal antibody (1:1000, clone KH95, sc251, Santa Cruz), RRM2 monoclonal antibody (1:1000, clone EPR11820, ab172476, Abcam), CDK2 pT14 monoclonal antibody (1:1000, clone EP2234Y, ab68265, Abcam), phospho-Histone H3 (Ser10) polyclonal antibody (1:1000, 06-570, EMD Millipore), PPIB polyclonal antibody (1:2000, ab16045, Abcam), BrdU (347580, BD Biosciences). Goat anti-rabbit IgG secondary antibody IRdye 800CW (925-32211, LI-COR), or goat anti- mouse secondary antibody IgG IRdye 680RD (925-68070, LI-COR).

\section{$\underline{\text { Immunostaining }}$}

Cells were washed once with 1x PBS and incubated with 100\% ice-cold methanol for 10 min, followed by three washes with PBS and incubation with ice cold 10\% formalin for $10 \mathrm{~min}$. Cells were then washed with PBS prior to blocking in PBS containing BSA 1\%, normal goat serum (1\%) and Triton X-100 (0.1\%) for minimum of $1 \mathrm{~h}$. Cells were incubated overnight $\left(4{ }^{\circ} \mathrm{C}\right)$ with primary antibodies to $\gamma \mathrm{H} 2 \mathrm{AX}(1: 1500)$, and/or $\mathrm{BrdU}(1: 200)$ diluted in PBS containing BSA and goat serum. The next day cells were washed three times with PBS and stained with the appropriate secondary antibodies conjugated to fluorophores (1:1200, Alexa Fluor488 [A11001] or Alexa Fluor657 [A21244], Thermo Fisher Scientific) in PBS containing BSA, goat serum and Hoechst $(10 \mu \mathrm{g} / \mathrm{ml})$ for $1 \mathrm{~h}$. After three washes with PBS cells were viewed and analysed using an INCell Analyzer 1000 automated epifluorescence microscope. 
Images of 1000 nuclei per well were acquired and nuclear staining was analysed using INCell analysis software (GE Healthcare UK Ltd).

To visualize single-stranded DNA (ssDNA), cells were cultured in $10 \mu \mathrm{M} \mathrm{BrdU}$ for $24 \mathrm{~h}$ before treatment. To label the S phase population, cells were either pulse-labeled with $10 \mu \mathrm{M}$ EdU for $1 \mathrm{~h}$ prior to fixation, or pre-treated for $1 \mathrm{~h}$ with $10 \mu \mathrm{M} \mathrm{EdU}$, followed by treatment for 6 or 24 $\mathrm{h}$ and processed with the Click-iT EdU Alexa Fluor 488 Imaging Kit according to manufacturer's instructions (C10338, Thermo Fisher Scientific).

\section{$\underline{\text { Flow cytometry analysis }}$}

Exponentially growing H1975 cells were treated with adefovir dipivoxil, VE822 or a combination for 2, 4, 6 and $24 \mathrm{~h}$. Prior to collection, cells were pulse labelled with $10 \mu \mathrm{M}$ BrdU for $30 \mathrm{~min}$, for the last $30 \mathrm{~min}$ of drug incubation. Medium as well as PBS washes were collected, and cells were trypsinised and fixed in ice-cold $70 \%$ ethanol. Cells were then resuspended in $2 \mathrm{M} \mathrm{HCl}$ with $0.5 \%$ Triton X-100 and incubated for $30 \mathrm{~min}$ at room temperature (RT). Subsequently, supernatant was re-suspended in $0.1 \mathrm{M}$ sodium tetraborate. Cells were washed with PBS containing 1\% BSA, and finally re-suspended in 1\% BSA and $0.5 \%$ Tween 20 in PBS containing primary BrdU (1:50) and phospho-Histone H3 (Ser10) (1:100) antibody and incubated overnight at $4{ }^{\circ} \mathrm{C}$. Cells were washed with $1 \%$ BSA in PBS and re-suspended in $1 \%$ BSA and $0.5 \%$ Tween 20 in PBS containing secondary antibody conjugated to Alexa488 fluorophore for $1 \mathrm{~h}$ at RT. Cells were then washed with $1 \%$ BSA, and re-suspended in PBS containing propidium iodide (PI, $10 \mu \mathrm{g} / \mathrm{ml})$ and RNaseA $(10 \mu \mathrm{g} / \mathrm{ml})$, followed by incubation for minimum of $30 \mathrm{~min}$ at RT. DNA content and BrdU incorporation were measured using a FACS Calibur Flow Cytometer (BD Biosciences) and BD CellQuestTM Pro Software. Analysis of the data was carried out using the FlowJo software (Tree Star Inc.).

\section{Statistical analysis:}

Statistical analyses using one way Anova with Bonferroni test or two way Anova with Tukey's multiple comparisons test were performed using GraphPad Prism version 8.0.1.

$\mathrm{N}=3$ indicates three independent biological experiments, each performed at least in triplicates. $\mathrm{P}<0.1=* ; \mathrm{P}<0.01=* * ; \mathrm{P}<0.001=* * *$.

\section{Data Availability:}

Data will be made available upon reasonable request. 
Results

\section{Adefovir dipivoxil together with an ATR inhibitor result in marked cytotoxicity towards tumour cells}

To identify potential combination therapies, we treated H1975 human lung adenocarcinoma cells with a combination of 1902 bioactive compounds and an ATRi (VE822) for 6 days. Compounds previously reported to synergise with ATR inhibition were identified from the screen: irinotecan ${ }^{16}$ (topoisomerase I inhibitor), olaparib ${ }^{27}$ (PARP1 inhibitor), and KU-60019 28 (ATM inhibitor), thereby corroborating our screening approach. The screen also identified adefovir dipivoxil, as the most cytotoxic compound in combination with VE822 (Figure 1). Adefovir dipivoxil (Hepsera) is a prodrug of adefovir, a reverse transcriptase inhibitor and nucleoside analogue. It is used in the clinic to treat patients with chronic hepatitis B (HBV) ${ }^{22-}$ 24. To determine whether the increased cytotoxicity of adefovir dipivoxil in the presence of VE822 extended to other cell lines, we treated H1975, A549, and PC9 with adefovir dipivoxil, or a combination of adefovir dipivoxil and VE822. Treatment with adefovir dipivoxil significantly reduced cell proliferation in all three cell lines, which was further decreased upon combination treatment with VE822 (Figure 2A-C). In order to confirm the effect of simultaneous adefovir dipivoxil treatment and ATR inhibition, we treated cells with another potent and selective ATR inhibitor- VE82 ${ }^{16}$. The results were consistent with the proliferation data seen with VE822 (Figure S1A). Reduction in proliferation was not observed when H1975 cells were treated with adefovir dipivoxil and an ATM inhibitor (KU55933) and was modest upon a combination treatment with a DNA-PKcs inhibitor (NU7441) (Figure S1B), indicating a specific synergy between adefovir dipivoxil and ATR inhibition. BRCA2 (breast cancer type 2) - deficient cells were also more sensitive to the treatment with adefovir dipivoxil, suggesting an involvement of homologous recombination (HR) pathway (Figure S1C). Treatment with adefovir (the mature form of adefovir dipivoxil), or cidofovir, another nucleoside analogue reverse transcriptase inhibitor ${ }^{29}$, did not result in reduction of cell proliferation (Figure S1D,E), which was expected since these compounds inefficiently enter into cells ${ }^{23,24}$. Modest reduction of proliferation was observed when NBE1 (normal bronchial epithelium 1) cells were treated with a combination of adefovir dipivoxil and VE822 (Figure S1F). This is not unexpected as NBE1 is a highly proliferative cell line, and therefore sensitive to inhibition of DNA synthesis. However, the impact of combined adefovir dipivoxil treatment and ATR inhibition appears much less than that of tumour cell lines.

To determine whether treatment with adefovir dipivoxil alone, or in combination with VE822, not only results in reduction of proliferation but also in decreased cell survival, colony formation assays were performed. The combination effect was most pronounced after 24 or $144 \mathrm{~h}$ of treatment, compared to DMSO control, whereas $2 \mathrm{~h}$ of treatment showed only a marginal reduction of viability (Figure 2D). Prolonged adefovir dipivoxil treatment, combined with VE822, was more effective in decreasing cell survival than treatment with adefovir dipivoxil alone (Figure 2D, Figure S1G). This is consistent with the proliferation data (Figure 2A-C) and suggests enhanced cytotoxicity. 


\section{Adefovir dipivoxil treatment attenuates DNA synthesis and induces DNA replication stress}

To further investigate the combination of adefovir dipivoxil and VE822 treatment, we examined effects on cell cycle by PI staining and BrdU-pulse labelling (Figure 3A; Figure $\mathrm{S} 2 \mathrm{~A}$ ). In cells treated for $24 \mathrm{~h}$, the proportion of replicating S-phase cells (BrdU positive) was reduced from $\sim 30 \%$ after DMSO or VE822 treatment to $\sim 14 \%$ (adefovir dipivoxil treatment) or $6 \%$ (combined adefovir dipivoxil and VE822 treatment). Consequently, the proportion of non-replicating S-phase cells ${ }^{30}$ increased from $\sim 5 \%$ in controls to $\sim 20$ and $25 \%$ in adefovir dipivoxil alone, or adefovir dipivoxil and VE822 treatment, respectively (Figure 3A,B). Therefore, these data suggest that adefovir dipivoxil is involved in attenuation of DNA synthesis. To research this further, we treated cells with adefovir dipivoxil, VE822 or a combination for 6 or $24 \mathrm{~h}$, labelled them with EdU and examined the cells by immunofluorescence (Figure 3C). Adefovir dipivoxil alone, or in combination with VE822, significantly reduced the percentage of EdU positive cells compared to DMSO, or VE822 treated controls. These results are consistent with the decrease in BrdU positive cells at $24 \mathrm{~h}$, as shown by flow cytometry data.

Next, we treated cells with adefovir dipivoxil alone, or in combination with VE822 for $24 \mathrm{~h}$, and looked for activation of ATR/ATM signalling and evidence of replication stress. Treatment with adefovir dipivoxil resulted in activation of ATR signalling, shown by an increase in phospho-CHK1 levels ${ }^{6}$. Activation of the ATR pathway was associated with downregulation of cyclin F, inactivation of cyclin dependent kinase 2 (CDK2) (manifested by its phosphorylation ${ }^{31}$ ), and increased levels of ribonucleotide reductase regulatory subunit M2 (RRM2) ${ }^{32}$. In contrast, adefovir dipivoxil and VE822 combination treatment resulted in decreased levels of cyclin F, phospho-CDK2 and RRM2, as well as upregulation of phosphoreplication protein A (RPA), a replication stress marker ${ }^{33}$, and $\gamma \mathrm{H} 2 \mathrm{AX}$, a DNA damage marker ${ }^{34}$ (Figure 3D). This is in line with published data, which has shown that CDK2 inhibitory phosphorylation is required for recovery from replication stress ${ }^{35}$. Moreover, adefovir dipivoxil treatment only marginally increased phospho-KAP1, indicating a low level of ATM signalling. However, strong activation of ATM signalling, shown by phospho-ATM, phosphoKAP1 and phospho-CHK2 ${ }^{36,37}$, was observed in the combination treatments, suggesting DSB formation ${ }^{16}$ (Figure 3D). Analogous biological effects were also seen when cells were treated with a 10x lower concentration of VE822 $(0.1 \mu \mathrm{M}$, used in the drug screen, Figure 1$)$, although the effects were not as marked (Figure S2 B,C). Incomplete suppression of phospho-CHK1 in samples treated with $0.1 \mu \mathrm{M}$ VE822 suggested only partial inhibition of ATR kinase activity at the lower concentration (Figure S2B). This indicates that higher concentrations of VE822 are required for more complete inhibition of ATR and activation of ATM signalling.

An apoptotic signal shown by cleaved PARP ${ }^{38}$ was also observed after combination treatment (Figure 3D). Additionally, adefovir dipivoxil prevented cells from progressing into mitosis, as shown by a low proportion of phospho-Histone H3 positive cells (Figure 3E). These data are consistent with adefovir dipivoxil treated cells accumulating in non-replicating S-phase (Figure $3 \mathrm{~A}, \mathrm{~B})$. Addition of VE822 resulted in pre-mature entry into mitosis ${ }^{16,39}$, compared to DMSO control. However, combination treatment (adefovir dipivoxil and VE822) did not result in a higher proportion of phospho-Histone $\mathrm{H} 3$ positive cells, compared to adefovir dipivoxil alone (Figure 3E). These data suggest that adefovir dipivoxil stalls cells in S phase thereby blocking cell cycle progression and subsequent mitotic entry. 


\section{ATR inhibition selectively kills cells under high replication stress}

To explore the role of adefovir dipivoxil in the induction of DNA replication stress, we investigated whether there were any similarities between adefovir dipivoxil and hydroxyurea (HU), an inhibitor of ribonucleotide reductase ${ }^{40,41}$. We compared cell cycle profiles after treatment with adefovir dipivoxil, HU or a combination of either drug with VE822. In both cases, $6 \mathrm{~h}$ of treatment reduced the proportion of BrdU positive cells, while $24 \mathrm{~h}$ of treatment completely abolished BrdU incorporation and increased the proportion of non-replicating Sphase cells compared to DMSO or VE822 control (Figure 4A,B; Figure S2E). In contrast, BrdU incorporation was unaffected by the exposure of cells to adefovir (the mature form of adefovir dipivoxil with poor cell penetration) (Figure 4C). To confirm activation of ATR signalling, we treated cells with adefovir dipivoxil, HU or gemcitabine (an analogue of deoxycytidine ${ }^{42}$ ) for $24 \mathrm{~h}$ (Figure 4D). Indeed, we observed increased phospho-CHK1 in cells treated with each of the drugs, which correlated with downregulation of cyclin F, CDK2 inactivation, as well as RRM2 and E2F1 upregulation. Consistent with published data, simultaneous drug treatment and ATR inhibition resulted in decreased levels of the above proteins ${ }^{14}$ (Figure 4D, Figure $\mathrm{S} 2 \mathrm{~F}$ ). Additionally, increased levels of cyclin A in cells treated with adefovir dipivoxil alone, or in combination with VE822, provide increased evidence for S-phase stalling, as suggested by flow cytometry analysis (Figure 3A).

To corroborate adefovir dipivoxil and VE822 combination treatment resulting in increased $\gamma \mathrm{H} 2 \mathrm{AX}$ protein levels (Figure 3D and 4D), we investigated $\gamma \mathrm{H} 2 \mathrm{AX}$ focus formation ${ }^{43}$. Exposure of cells to adefovir dipivoxil and ATR inhibition resulted in increased number of $\gamma \mathrm{H} 2 \mathrm{AX}$ foci compared to control, but not to the adefovir dipivoxil treatment alone (Figure $\mathrm{S} 3 \mathrm{~A}$ ), however marked differences were observed in the numbers of pan-nuclear $\gamma \mathrm{H} 2 \mathrm{AX}$ positive cells. A large proportion of cells $(\sim 40 \%)$ was pan-nuclear $\gamma \mathrm{H} 2 \mathrm{AX}$ positive after $24 \mathrm{~h}$ of adefovir dipivoxil and VE822 combination treatment (Figure S3B). Similarly, exposure to $\mathrm{HU}$ or gemcitabine, induced pan-nuclear $\gamma \mathrm{H} 2 \mathrm{AX}$ positive cells (Figure S3C). In contrast, as expected, treatment with mature drug, adefovir, did not result in pan-nuclear $\gamma \mathrm{H} 2 \mathrm{AX}$ formation. Pan-nuclear $\gamma \mathrm{H} 2 \mathrm{AX}$, specifically located in S-phase cells, has been described as a common feature of replication catastrophe-associated DNA damage, caused by RPA exhaustion ${ }^{44}$. To test whether we could observe this phenotype, we labelled cells with EdU 1 $\mathrm{h}$ prior to treatment with adefovir dipivoxil alone, or a combination with VE822 (Figure 5). Exposure of cells to adefovir dipivoxil and ATR inhibition for $6 \mathrm{~h}$ resulted in approximately $20 \%$ pan-nuclear $\gamma \mathrm{H} 2 \mathrm{AX}$ positive cells, almost entirely located in S-phase. The $24 \mathrm{~h}$ combination treatment showed $50 \%$ pan-nuclear $\gamma \mathrm{H} 2 \mathrm{AX}$ positive cells, however the percentage of EdU positive cells did not change compared to the $6 \mathrm{~h}$ time point. This could be due to a proportion of cells entering S-phase post EdU labelling and therefore remaining EdU negative (Figure 5A-C). Consistent with an increase in pan-nuclear $\gamma \mathrm{H} 2 \mathrm{AX}$ positive cells, following adefovir dipivoxil and VE822 treatment, we observed increased levels of ssDNA, shown as BrdU labelled DNA (Figure 5D,E). These data are consistent with elevated levels of ssDNA observed after treatment with $\mathrm{HU}$ or gemcitabine ${ }^{14}$, and strongly suggest that adefovir dipivoxil induces DNA replication stress.

Our results indicate that adefovir dipivoxil in combination treatment with ATRi leads to enhanced cytotoxicity towards cancer cells, compared to non-malignant cells, and may lead to replication catastrophe. In addition, our data may provide additional support for the concept that ATR inhibition selectively kills cells under high replication stress ${ }^{1,14}$. Figure 5F illustrates a proposed mechanism of adefovir dipivoxil cytotoxicity in combination with ATR inhibition. 


\section{Discussion}

Cells experience naturally occurring DNA damage throughout the cell cycle ${ }^{2}$. Replication stress, a complex phenomenon, featuring stalled replication forks with regions of ssDNA, is a type of DNA damage that can lead to DSBs ${ }^{45}$. ATR signalling, one of the DDR pathways, mediates replication stress response by stabilising stalled replication forks, counteracting new origin firing, and leading to cell cycle delays, thereby preventing genome instability 5, 6 . Replication stress, is a known feature of cancer cells, making ATR inhibition of great interest for cancer treatment ${ }^{16}$. VE822, currently in phase I clinical trials (ClinicalTrials.gov: NCT02157792), is a highly specific ATR inhibitor, which sensitises cancer cells, but not normal cells, to DNA damaging drugs, like gemcitabine, or irinotecan ${ }^{15,16}$. Due to emergence of resistance to DDR inhibitors, used in clinic for anti-cancer chemotherapies ${ }^{17-20}$, combination treatments are favourable to provide sustained cancer growth inhibition ${ }^{21}$.

We performed a small molecule drug screen with VE822 to find a combination drug that has increased cytotoxicity in the presence of ATR inhibition. Adefovir dipivoxil was identified as a compound that has the greatest combination effect with VE822. It is a di-ester prodrug, rapidly converted inside the cell into adefovir ${ }^{23}$, an analogue of adenosine monophosphate. Adefovir requires phosphorylation to become an active metabolite - adefovir diphosphate, which inhibits reverse transcriptase, leading to DNA chain termination and inhibition of viral replication ${ }^{24}$. Adefovir dipivoxil (Hepsera) is used in the clinic to treat patients with chronic hepatitis B (HBV) 2422 .

Adefovir dipivoxil's increased cytotoxicity in the presence of VE822 was very apparent in all 3 tested cell lines. The combination treatment with adefovir dipivoxil and VE822 significantly reduced proliferation of the H1975, A549, and PC9 cell lines, compared to adefovir dipivoxil alone. Moreover, adefovir dipivoxil and VE822 combination treatment (24 and $144 \mathrm{~h}$ ) was more effective in inducing cell death than treatment with adefovir dipivoxil alone, as shown by the colony formation assay. Proliferation assays demonstrated that this enhancement was not present with adefovir dipivoxil and ATM inhibition, and was modest with adefovir dipivoxil and DNA-PKcs inhibition. Thus, our results indicate a highly selective effect of adefovir dipivoxil and ATR inhibition.

In addition, exposure of cells to adefovir dipivoxil, or adefovir dipivoxil and VE822 combination (24 h), inhibited DNA synthesis and increased the number of non-replicating Sphase cells ${ }^{30}$. The combined treatment with adefovir dipivoxil and VE822 was more effective in inhibiting BrdU incorporation then adefovir dipivoxil alone. This significant S-phase stalling in cells treated with adefovir dipivoxil alone, or together with VE822, was confirmed by EdU labelling. Consistent with these data, low level of phospho-HH3 protein was observed after treatment with adefovir dipivoxil, indicating delayed progression into mitosis. Phospho-HH3 remained low despite simultaneous ATR inhibition, which can cause pre-mature entry into mitosis 16,39 .

We observed that adefovir dipivoxil treatment activated ATR signalling, which correlated with downregulation of cyclin F, CDK2 inactivation and accumulation of RRM2. This result is consistent with published data, where upon genotoxic stress, cyclin F is downregulated to allow RRM2 accumulation in an ATR-dependant manner ${ }^{32}$. However, adefovir dipivoxil and VE822 combination treatment resulted in decreased levels of cyclin F and RRM2 expression, 
suggesting that there is no direct link between these two proteins. Moreover, our results showed that inhibition of ATR-CHK1 signalling leads to downregulation of RRM2 and E2F. This is in line with published data, where authors suggested correlation between ATR inhibition and low levels of RRM2, and speculated that ATR might play a significant role in promoting synthesis of dNTPs ${ }^{14}$. Our results, showing activation of ATR signalling after HU or gemcitabine treatment (both associated with imbalance of dNTPs), support this speculation. Therefore, our data suggest that simultaneous adefovir dipivoxil treatment and ATR inhibition, creates an imbalance between demand for, and availability of dNTPs, resulting in increased replication stress. Exposure to replication stress inducers $(24 \mathrm{~h})$, caused activation of ATM signalling and $\gamma \mathrm{H} 2 \mathrm{AX}$ accumulation, strongly indicating presence of irreparable DSBs, possibly due to collapsed replication forks $32,35,46,47$. Importantly, the differences observed between adefovir dipivoxil single treatment, and combination treatment with VE822 are not solely due to changes in cell cycle, as both treatments arrested cells in non-replicating S-phase. Due to large numbers of early replication origins, elevated levels of ssDNA, and high demand for dNTPs, ATR is essential in early S-phase, as well as during replication stress ${ }^{14,48}$. We have shown that adefovir dipivoxil, similar to HU treatment, stalls cells in S-phase. Cells stalled in S-phase, harbouring elevated levels of DNA damage could be subject to replication catastrophe 44. Characteristics of replication catastrophe, believed to be caused by RPA exhaustion, include pan-nuclear $\gamma \mathrm{H} 2 \mathrm{AX}$, specifically in S-phase cells, as well as accumulation of ssDNA ${ }^{1,44}$. Our results have shown that simultaneous S-phase stalling, induced by adefovir dipivoxil, and ATR inhibition, caused significant increase in pan-nuclear $\gamma \mathrm{H} 2 \mathrm{AX}$ positive cells, almost entirely located in S-phase. Moreover, this result corresponded to marked induction of ssDNA accumulation, caused by the combination treatment, pointing towards replication catastrophe as a possible mechanism of cell death, and suggesting that ATRi selectively kills cells under high replication stress. Interestingly, we also found that cells harbouring deficiency in the HR pathway (BRCA2-deficient cells) are more sensitive to adefovir dipivoxil than HR-proficient cells (BRCA2-proficient cells), suggesting that adefovir dipivoxil associated cytotoxic lesions are resolved in an HR dependent manner ${ }^{49}$.

Taken together our data support a model where adefovir dipivoxil induced inhibition of DNA synthesis in the presence of marked ATR inhibition leads to collapsed replication forks, subsequent ATM activation and cell death. Notably, the effects of lower concentrations of VE822 and adefovir dipivoxil appear predominantly anti-proliferative rather than cytotoxic. This suggests that the mechanism of the combined effects of these two drugs has a significant concentration-dependency, with cytotoxicity dominating at the higher dose levels, where our proposed model may be most relevant.

Similarities between adefovir dipivoxil, HU and gemcitabine suggest that imbalance in dNTP pools may be a mechanism underlying the interaction between adefovir dipivoxil and ATR inhibition. Our results are also consistent with published data, showing that in the event of replication stress, inhibition of ATR relieves the suppression of ssDNA accumulation, leading to DNA damage, ATM recruitment and replication catastrophe ${ }^{1,50}$. Moreover, our data adds to growing evidence that targeting cells under high DNA replication stress can increase tumour cell killing by ATR inhibition 1,14,32. Finally, we demonstrate that repurposing adefovir dipivoxil, as a replication stress inducer, enhances the cytotoxic effect of ATR inhibition, which may have clinical implications.

Authors declare no conflict of interest. 


\section{References}

1. Toledo LI, Altmeyer M, Rask MB, Lukas C, Larsen DH, Povlsen LK, Bekker-Jensen S, Mailand $\mathrm{N}$, Bartek J, Lukas J. ATR prohibits replication catastrophe by preventing global exhaustion of RPA. Cell 2013;155:1088-103.

2. Halazonetis TD, Gorgoulis VG, Bartek J. An oncogene-induced DNA damage model for cancer development. Science (New York, N.Y.) 2008;319:1352-5.

3. Ciccia A, Elledge SJ. The DNA damage response: making it safe to play with knives. Molecular cell 2010;40:179-204.

4. Jackson SP, Bartek J. The DNA-damage response in human biology and disease. Nature 2009;461:1071-78.

5. Friedel AM, Pike BL, Gasser SM. ATR/Mec1: coordinating fork stability and repair. Current opinion in cell biology 2009;21:237-44.

6. Sorensen CS, Syljuasen RG. Safeguarding genome integrity: the checkpoint kinases ATR, CHK1 and WEE1 restrain CDK activity during normal DNA replication. Nucleic acids research 2012;40:477-86.

7. Lambert S, Carr AM. Checkpoint responses to replication fork barriers. Biochimie 2005;87:591-602.

8. Tercero JA, Longhese MP, Diffley JF. A central role for DNA replication forks in checkpoint activation and response. Molecular cell 2003;11:1323-36.

9. Kass EM, Jasin M. Collaboration and competition between DNA double-strand break repair pathways. FEBS letters 2010;584:3703-8.

10. Trenz K, Smith E, Smith S, Costanzo V. ATM and ATR promote Mre11 dependent restart of collapsed replication forks and prevent accumulation of DNA breaks. The EMBO journal 2006;25:1764-74.

11. Couch FB, Bansbach CE, Driscoll R, Luzwick JW, Glick GG, Betous R, Carroll CM, Jung SY, Qin J, Cimprich KA, Cortez D. ATR phosphorylates SMARCAL1 to prevent replication fork collapse. Genes Dev 2013;27:1610-23.

12. Ragland RL, Patel S, Rivard RS, Smith K, Peters AA, Bielinsky AK, Brown EJ. RNF4 and PLK1 are required for replication fork collapse in ATR-deficient cells. Genes Dev 2013;27:2259-73.

13. Petermann $E$, Woodcock $M$, Helleday T. Chk1 promotes replication fork progression by controlling replication initiation. Proc Natl Acad Sci U S A 2010;107:16090-5.

14. Buisson R, Boisvert JL, Benes CH, Zou L. Distinct but Concerted Roles of ATR, DNA-PK, and Chk1 in Countering Replication Stress during S Phase. Molecular cell 2015;59:1011-24.

15. Fokas E, Prevo R, Pollard JR, Reaper PM, Charlton PA, Cornelissen B, Vallis KA, Hammond EM, Olcina MM, Gillies McKenna W, Muschel RJ, Brunner TB. Targeting ATR in vivo using the novel inhibitor VE-822 results in selective sensitization of pancreatic tumors to radiation. Cell death \& disease 2012;3:e441.

16. Weber AM, Ryan AJ. ATM and ATR as therapeutic targets in cancer. Pharmacology \& therapeutics 2015;149:124-38.

17. Lynch TJ, Bell DW, Sordella R, Gurubhagavatula S, Okimoto RA, Brannigan BW, Harris PL, Haserlat SM, Supko JG, Haluska FG, Louis DN, Christiani DC, et al. Activating mutations in the epidermal growth factor receptor underlying responsiveness of non-small-cell lung cancer to gefitinib. The New England journal of medicine 2004;350:2129-39.

18. Pao W, Miller V, Zakowski M, Doherty J, Politi K, Sarkaria I, Singh B, Heelan R, Rusch V, Fulton L, Mardis E, Kupfer D, et al. EGF receptor gene mutations are common in lung cancers from "never smokers" and are associated with sensitivity of tumors to gefitinib and erlotinib. Proceedings of the National Academy of Sciences of the United States of America 2004;101:13306-11. 
19. Cross DAE, Ashton SE, Ghiorghiu S, Eberlein C, Nebhan CA, Spitzler PJ, Orme JP, Finlay MRV, Ward RA, Mellor MJ, Hughes G, Rahi A, et al. AZD9291, an irreversible EGFR TKI, overcomes T790M-mediated resistance to EGFR inhibitors in lung cancer. Cancer discovery 2014;4:1046-61.

20. Foo J, Michor F. Evolution of acquired resistance to anti-cancer therapy. Journal of Theoretical Biology 2014;355:10-20.

21. Roskoski R, Jr. The ErbB/HER family of protein-tyrosine kinases and cancer. Pharmacological research 2014;79:34-74.

22. Angus $P$, Vaughan $R$, Xiong $S$, Yang $H$, Delaney $W$, Gibbs $C$, Brosgart $C$, Colledge $D$, Edwards R, Ayres A, Bartholomeusz A, Locarnini S. Resistance to adefovir dipivoxil therapy associated with the selection of a novel mutation in the HBV polymerase. Gastroenterology 2003;125:292-97.

23. Noble S, Goa KL. Adefovir dipivoxil. Drugs 1999;58:479-87; discussion 88-9.

24. Qaqish RB, Mattes KA, Ritchie DJ. Adefovir dipivoxil: A new antiviral agent for the treatment of hepatitis B virus infection. Clinical Therapeutics 2003;25:3084-99.

25. Bokobza SM, Jiang Y, Weber AM, Devery AM, Ryan AJ. Combining AKT inhibition with chloroquine and gefitinib prevents compensatory autophagy and induces cell death in EGFR mutated NSCLC cells. Oncotarget 2014;5:4765-78.

26. Ishikawa Y, Kozakai T, Morita H, Saida K, Oka S, Masuo Y. Rapid detection of mycoplasma contamination in cell cultures using SYBR Green-based real-time polymerase chain reaction. In vitro cellular \& developmental biology. Animal 2006;42:63-9.

27. Yazinski SA, Comaills V, Buisson R, Genois M-M, Nguyen HD, Ho CK, Todorova Kwan T, Morris R, Lauffer S, Nussenzweig A, Ramaswamy S, Benes $\mathrm{CH}$, et al. ATR inhibition disrupts rewired homologous recombination and fork protection pathways in PARP inhibitor-resistant BRCA-deficient cancer cells. Genes \& development 2017;31:318-32.

28. Shi Q, Shen LY, Dong B, Fu H, Kang XZ, Yang YB, Dai L, Yan WP, Xiong HC, Liang Z, Chen $\mathrm{KN}$. The identification of the ATR inhibitor VE-822 as a therapeutic strategy for enhancing cisplatin chemosensitivity in esophageal squamous cell carcinoma. Cancer letters 2018;432:56-68.

29. De Clercq E. Clinical potential of the acyclic nucleoside phosphonates cidofovir, adefovir, and tenofovir in treatment of DNA virus and retrovirus infections. Clinical microbiology reviews 2003;16:569-96.

30. Pfister SX, Markkanen E, Jiang Y, Sarkar S, Woodcock M, Orlando G, Mavrommati I, Pai CC, Zalmas LP, Drobnitzky N, Dianov GL, Verrill C, et al. Inhibiting WEE1 Selectively Kills Histone H3K36me3-Deficient Cancers by dNTP Starvation. Cancer cell 2015;28:557-68.

31. Parker LL, Piwnica-Worms H. Inactivation of the p34cdc2-cyclin B complex by the human WEE1 tyrosine kinase. Science (New York, N.Y.) 1992;257:1955-7.

32. D'Angiolella V, Donato V, Forrester FM, Jeong YT, Pellacani C, Kudo Y, Saraf A, Florens L, Washburn MP, Pagano M. Cyclin F-mediated degradation of ribonucleotide reductase M2 controls genome integrity and DNA repair. Cell 2012;149:1023-34.

33. Liaw H, Lee D, Myung K. DNA-PK-dependent RPA2 hyperphosphorylation facilitates DNA repair and suppresses sister chromatid exchange. PloS one 2011;6:e21424.

34. Furuta T, Takemura H, Liao ZY, Aune GJ, Redon C, Sedelnikova OA, Pilch DR, Rogakou EP, Celeste A, Chen HT, Nussenzweig A, Aladjem MI, et al. Phosphorylation of histone H2AX and activation of Mre11, Rad50, and Nbs1 in response to replication-dependent DNA double-strand breaks induced by mammalian DNA topoisomerase I cleavage complexes. The Journal of biological chemistry 2003;278:20303-12.

35. Hughes BT, Sidorova J, Swanger J, Monnat RJ, Jr., Clurman BE. Essential role for Cdk2 inhibitory phosphorylation during replication stress revealed by a human Cdk2 knockin mutation. Proceedings of the National Academy of Sciences of the United States of America 2013;110:8954-59.

36. Shiloh Y, Ziv Y. The ATM protein kinase: regulating the cellular response to genotoxic stress, and more. Nature reviews. Molecular cell biology 2013;14:197-210. 
37. Guo K, Shelat AA, Guy RK, Kastan MB. Development of a cell-based, high-throughput screening assay for ATM kinase inhibitors. Journal of biomolecular screening 2014;19:538-46.

38. Bokobza SM, Jiang Y, Weber AM, Devery AM, Ryan AJ. Short-Course Treatment With Gefitinib Enhances Curative Potential of Radiation Therapy in a Mouse Model of Human Non-Small Cell Lung Cancer. International Journal of Radiation Oncology*Biology*Physics 2014;88:947-54.

39. Canman CE. Replication checkpoint: Preventing mitotic catastrophe. Current Biology 2001;11:R121-R24.

40. Enoch T, Nurse P. Mutation of fission yeast cell cycle control genes abolishes dependence of mitosis on DNA replication. Cell 1990;60:665-73.

41. Rowley R, Subramani S, Young PG. Checkpoint controls in Schizosaccharomyces pombe: rad1. The EMBO journal 1992;11:1335-42.

42. Marasini B, Sahu RP. Natural Anti-Cancer Agents: Implications in Gemcitabine-Resistant Pancreatic Cancer Treatment. Mini reviews in medicinal chemistry 2017;17:920-27.

43. Rogakou EP, Boon C, Redon C, Bonner WM. Megabase chromatin domains involved in DNA double-strand breaks in vivo. The Journal of cell biology 1999;146:905-16.

44. Toledo L, Neelsen KJ, Lukas J. Replication Catastrophe: When a Checkpoint Fails because of Exhaustion. Molecular cell 2017;66:735-49.

45. Zeman MK, Cimprich KA. Causes and consequences of replication stress. Nature cell biology 2014;16:2-9.

46. Beck H, Nähse-Kumpf V, Larsen MSY, O'Hanlon KA, Patzke S, Holmberg C, Mejlvang J, Groth A, Nielsen O, Syljuåsen RG, Sørensen CS. Cyclin-dependent kinase suppression by WEE1 kinase protects the genome through control of replication initiation and nucleotide consumption. Molecular and cellular biology 2012;32:4226-36.

47. Cimprich KA, Cortez D. ATR: an essential regulator of genome integrity. Nature reviews. Molecular cell biology 2008;9:616-27.

48. Rhind N, Gilbert DM. DNA replication timing. Cold Spring Harbor perspectives in biology 2013;5:a010132.

49. Yajima $H$, Fujisawa $H$, Nakajima NI, Hirakawa $H$, Jeggo PA, Okayasu R, Fujimori A. The complexity of DNA double strand breaks is a critical factor enhancing end-resection. DNA repair 2013;12:936-46.

50. Stiff T, Walker SA, Cerosaletti K, Goodarzi AA, Petermann E, Concannon P, O'Driscoll M, Jeggo PA. ATR-dependent phosphorylation and activation of ATM in response to UV treatment or replication fork stalling. The EMBO journal 2006;25:5775-82. 


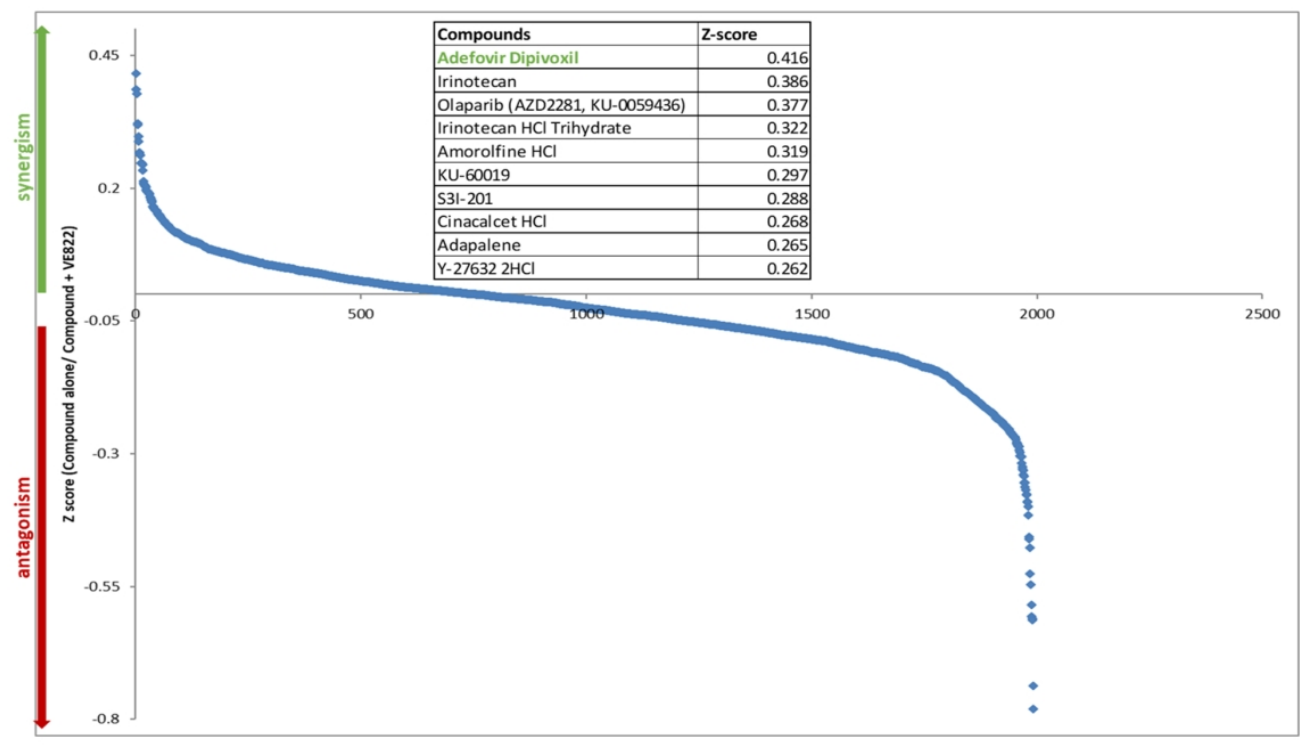

Figure 1. Compound screen.

Average $Z$ score for $\mathrm{H} 1975$ cell line treated with a combination of 1902 compounds ( $1 \mu \mathrm{M})$ and VE822 $(0.1 \mu \mathrm{M})$, ranked from most to least synergistic. Cell viability was assessed on day 6 post treatment using resazurin. Compound effect was calculated relative to either DMSO (treatment with compounds alone) or relative to VE822 (treatment with compounds and VE822). Z-scores were calculated as an average of log10 relative proliferation ([compounds alone]/[compounds+VE822]) The table shows the top 10 hits, ranked from the highest to the lowest Z-score. The complete list is shown in Table S1.

$519 \times 295 \mathrm{~mm}(96 \times 96 \mathrm{DPI})$ 
D
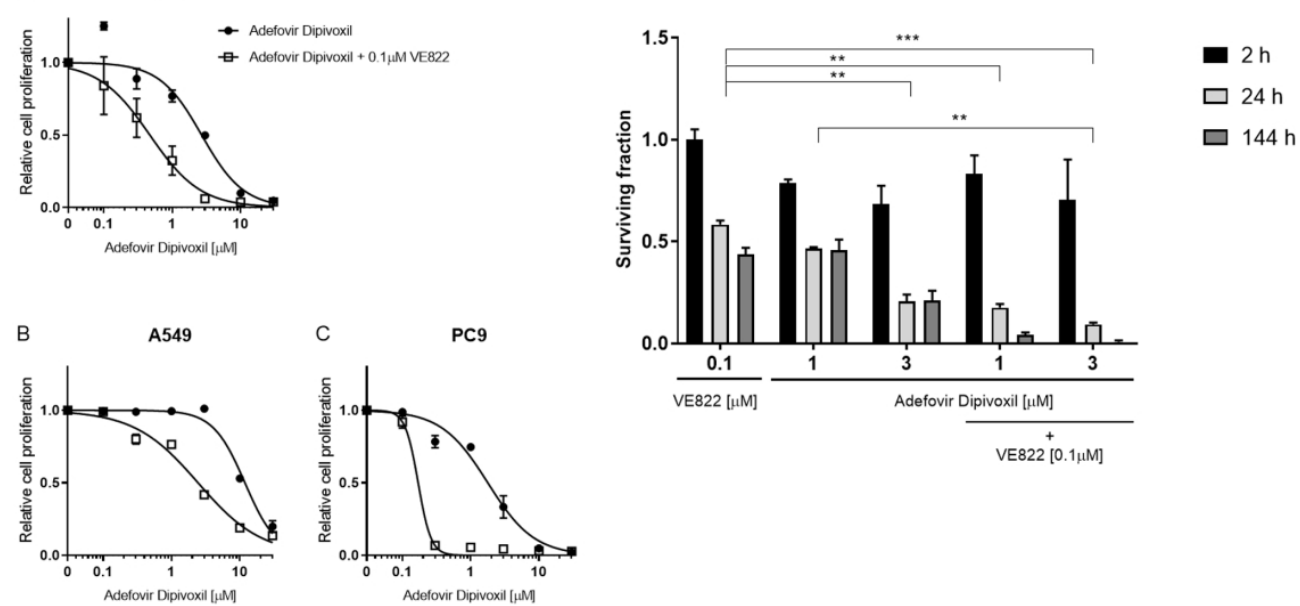

Figure 2. Adefovir dipivoxil, in combination with VE822, has increased cytotoxicity in human non-small cell lung cancer cell lines.

H1975 (A), A549 (B), PC9 (C) cell lines were treated with 0.03 - $30 \mu$ M adefovir dipivoxil or a combination of adefovir dipivoxil and VE822 for 6 days. On day 6 a resazurin proliferation assay was performed. The graphs show cell proliferation relative to DMSO (cells treated with adefovir dipivoxil alone), or relative to VE822 alone (cells treated with a combination of adefovir dipivoxil and VE822). The relative cell proliferation of VE822 (0.1 $\mu \mathrm{M})$ alone was $0.75,1$, and 0.7 in H1975 (A), A549 (B), PC9 (C), respectively. IC50 values for adefovir dipivoxil and adefovir dipivoxil $+0.1 \mu \mathrm{M}$ VE822 respectively: (A) $2.68 \mu \mathrm{M}, 0.46 \mu \mathrm{M}$; (B) $11.84 \mu \mathrm{M}$, $2.44 \mu \mathrm{M}$; (C) $1.77 \mu \mathrm{M}, 0.16 \mu \mathrm{M}$. D: Combination of adefovir dipivoxil and VE822 reduces clonogenic survival after 24 and $144 \mathrm{~h}$ of treatment. $\mathrm{H} 1975$ cells were treated with adefovir dipivoxil alone or in combination with VE822 for 2, 24 or $144 \mathrm{~h}$. Medium was then changed and colonies were left to grow for 2 weeks. Data points are normalised to DMSO control and are expressed as means \pm SEM; $\mathrm{P}<0.01=* * ; \mathrm{P}<0.001=* * *$.

$550 \times 268 \mathrm{~mm}(96 \times 96 \mathrm{DPI})$ 

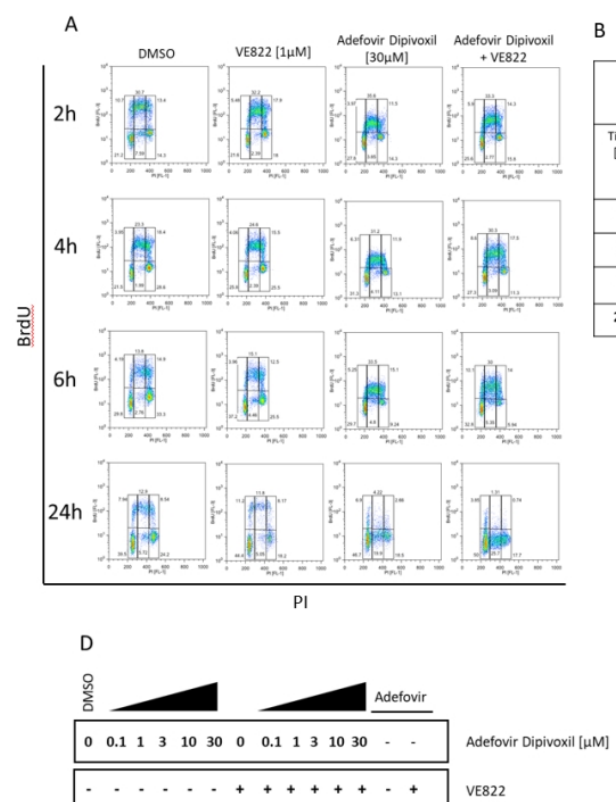

B
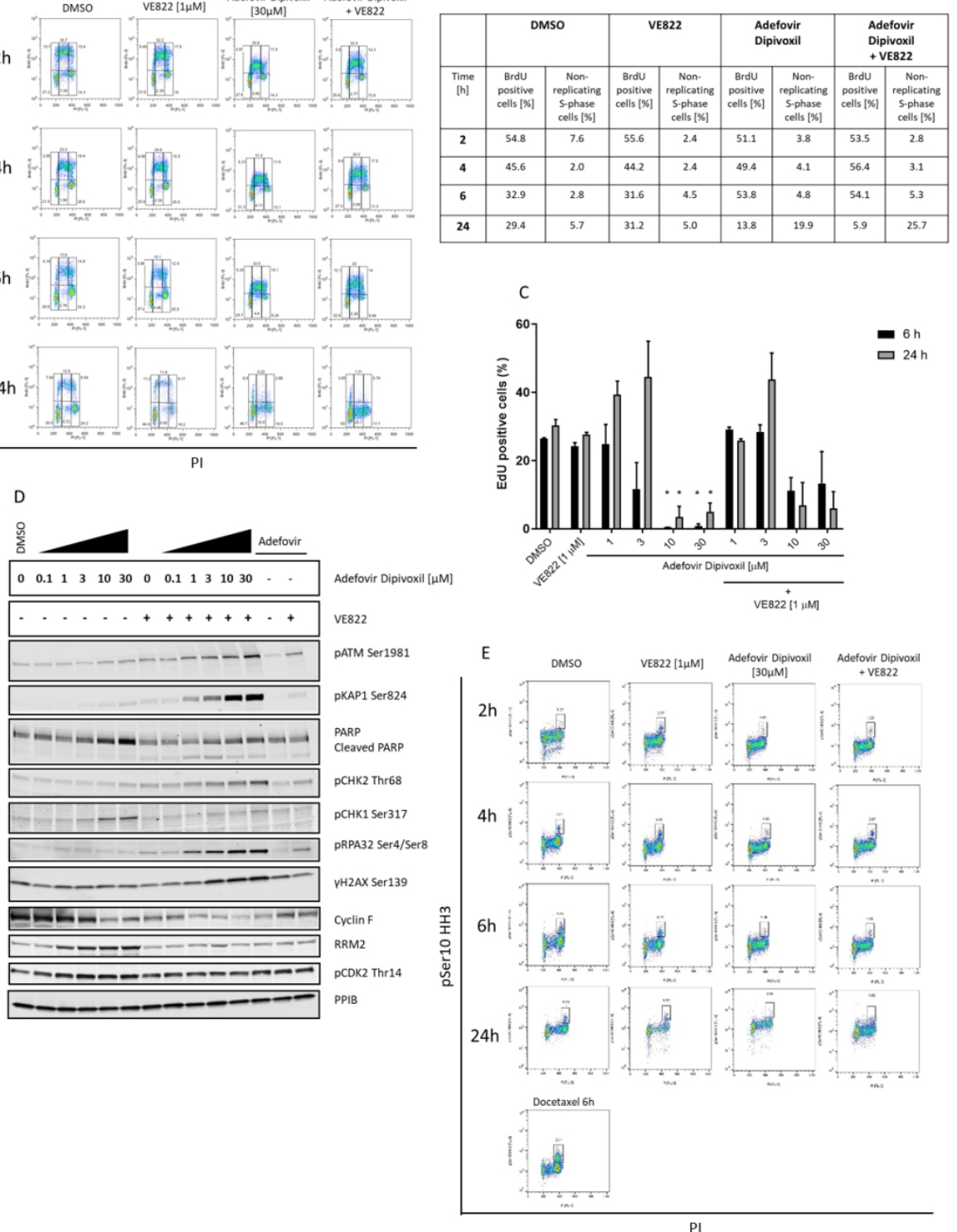

Figure 3. Treatment with adefovir dipivoxil and VE822 attenuates DNA synthesis and induces replication stress.

A: H1975 cells were treated with adefovir dipivoxil, VE822, or a combination for 2, 4, 6 or $24 \mathrm{~h}$. Prior to collection, cells were pulse labelled with $10 \mu \mathrm{M}$ BrdU for the last 30 min of drug incubation, they were then fixed and stained with PI and anti-BrdU antibody for flow cytometry analysis. The three lower gates in each chart represent unlabelled cell populations in (from left to right): G1-, S and G2/M-phase of the cell cycle.

The upper gates represent (from left to right): early-S-, intra-S- and late-S- /early G2-phase cell populations. DMSO was used as a control for the treatment. B: The table shows the total number of BrdU positive cells as well as the number of non-replicating S-phase cells at different time points upon treatment with adefovir dipivoxil, VE822, or a combination. C: H1975 cells were treated with stated concentrations of adefovir dipivoxil alone or in combination with VE822 for 6 or 24 h. Prior to collection cells, were pulse labelled with $10 \mu \mathrm{M}$ EdU for $1 \mathrm{~h}$ and fixed; The Figure shows percentage of EdU positive cells after treatment. Data points are expressed as means $\pm \mathrm{SEM} ; \mathrm{P}<0.1=*$. D: Cells were treated with stated concentrations of adefovir dipivoxil, adefovir alone or a combination with VE822 for $24 \mathrm{~h}$. PPIB was used as a loading control 
(only one representative loading control is shown) and DMSO was used as a biological control. E: H1975 cells were treated with adefovir dipivoxil, VE822, or a combination for 2, 4, 6 or $24 \mathrm{~h}$, they were then fixed and stained with anti- phospho-Histone H3 (Ser10) antibody for flow cytometry analysis; docetaxel was used as a positive control.

$189 \times 246 \mathrm{~mm}(168 \times 168 \mathrm{DPI})$ 

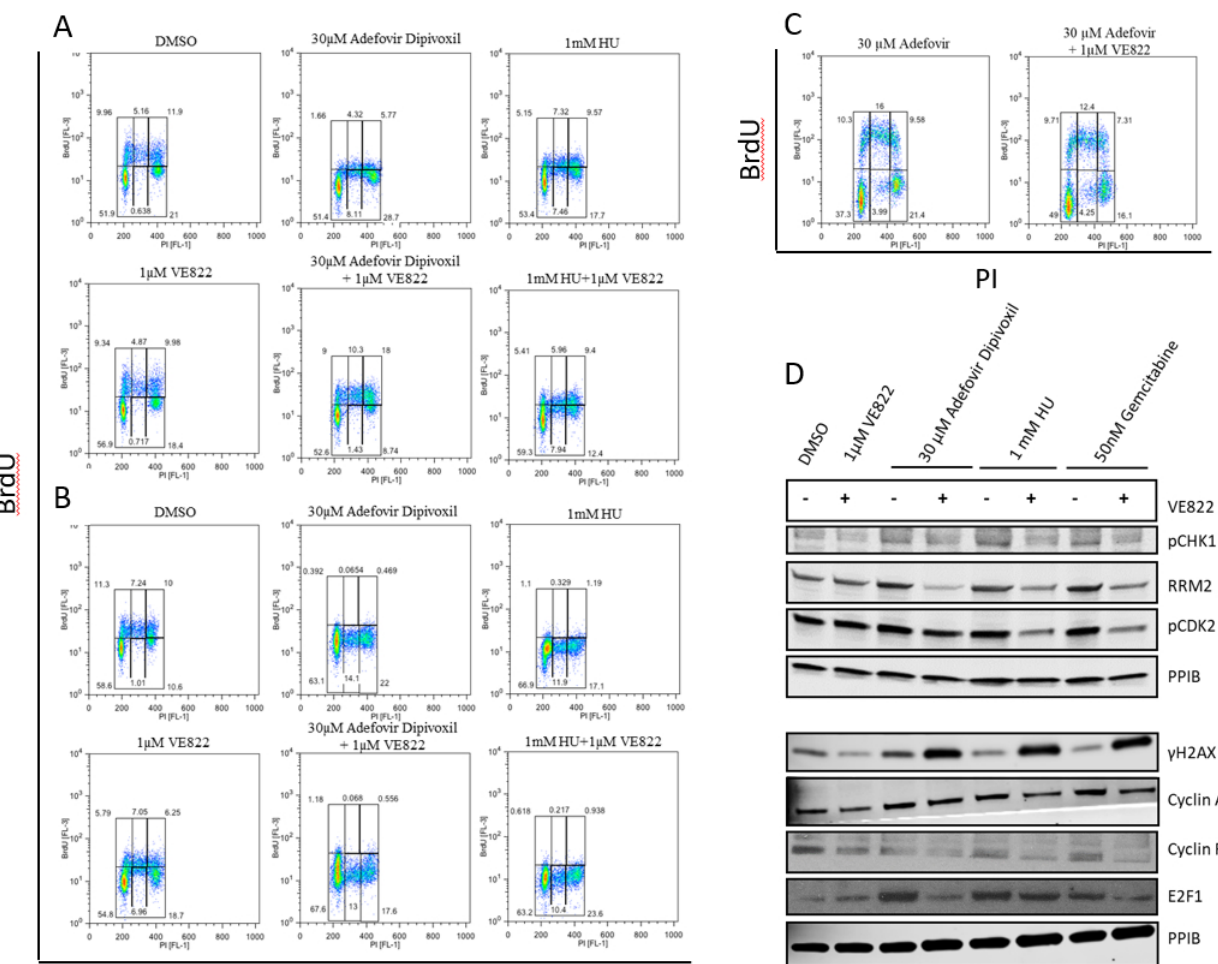

PI

Figure 4. Similarities in cell cycle distribution and ATR activation between adefovir dipivoxil, HU and gemcitabine treatment.

H1975 cells were treated with adefovir dipivoxil, HU or adefovir alone, or in combination with VE822 for 6 (A) or $24 \mathrm{~h}(\mathrm{~B}, \mathrm{C})$. Prior to collection, cells were pulse labelled with $10 \mu \mathrm{M}$ BrdU for the last $30 \mathrm{~min}$ of drug incubation, they were then fixed and stained with PI and anti-BrdU antibody for flow cytometry analysis. The three lower gates represent unlabelled cell populations in (from left to right): G1-, S and G2/M-phase of the cell cycle. The upper gates represent (from left to right): early-S-, intra-S- and late-S- /early G2-phase cell populations. DMSO was used as a treatment control. D: Cells were treated with stated concentrations of adefovir dipivoxil, $\mathrm{HU}$ or gemcitabine alone or in combination with VE822 for $24 \mathrm{~h}$. PPIB was used as a loading control and DMSO was used as a biological control.

\section{$163 \times 128 \mathrm{~mm}(168 \times 168 \mathrm{DPI})$}



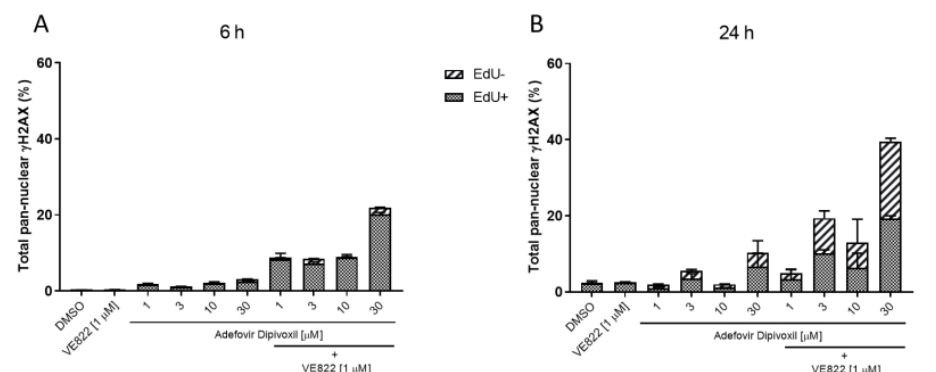

C DMSO EdU
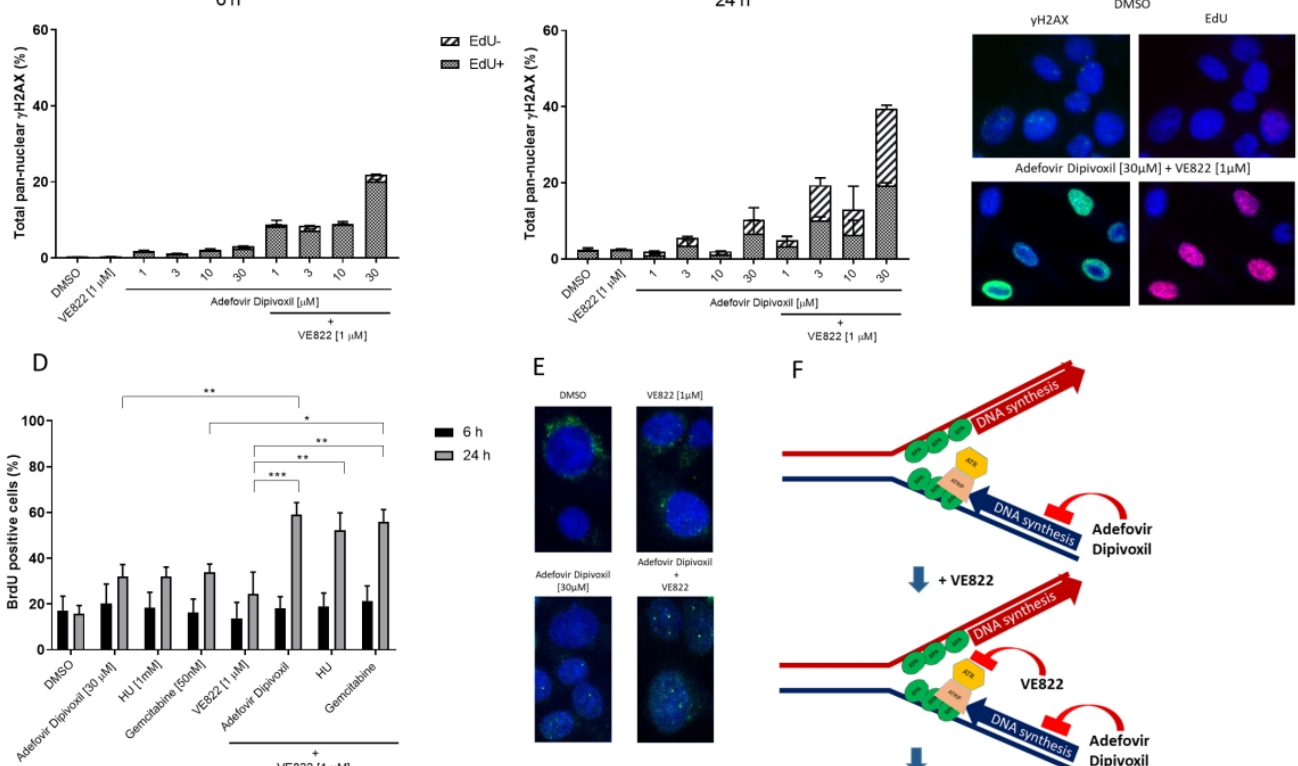

$\mathrm{F}$

F
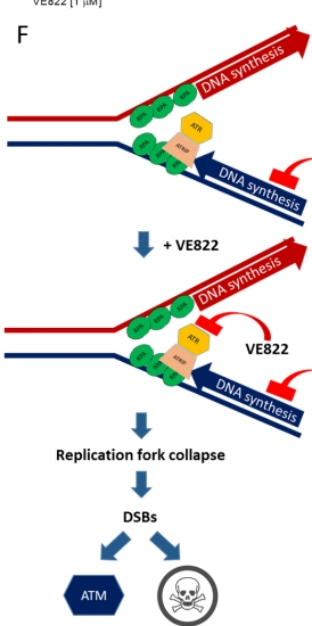

Figure 5. Adefovir dipivoxil and VE822 treatment induces pan-nuclear yH2AX expression, and increases SSDNA accumulation.

A, B: Percentage of total pan-nuclear yH2AX; H1975 cells were pulse labelled with $10 \mu \mathrm{M}$ EdU for $1 \mathrm{~h}$, washed and treated with adefovir dipivoxil alone or in combination with VE822 for 6 (A) or $24 \mathrm{~h}$ (B). Cells were then fixed and stained for $y \mathrm{H} 2 \mathrm{AX}$ ('EdU-'+ 'EdU+'= total pan-nuclear yH2AX). C: Representative images of cells treated with DMSO or adefovir dipivoxil + VE822 for $24 \mathrm{~h}$ (EdU positive cells in red, pannuclear yH2AX positive cells in green); 'EdU+' cells positive for pan-nuclear yH2AX and EdU; 'EdU-' cells positive for pan-nuclear yH2AX and negative for EdU. D: Percentage of BrdU positive cells ( $\geq 1$ foci/ cell); $\mathrm{H} 1975$ cells were cultured in $10 \mu \mathrm{M}$ BrdU for $24 \mathrm{~h}$ prior to treatment with indicated drugs for 6 or $24 \mathrm{~h}$. Cells were then fixed and ssDNA was detected using a BrdU antibody. E: Representative images of BrdU staining after $24 \mathrm{~h}$ treatment with indicated drugs. Data points are expressed as means $\pm S E M$; $P<0.1=*$; $\mathrm{P}<0.01=* * ; \mathrm{P}<0.001=* * * . \mathrm{F}$ : Proposed mechanism of adefovir dipivoxil cytotoxicity in combination with

ATR inhibition. Adefovir dipivoxil induces inhibition of DNA synthesis, leading to replication stress, and extended stretches of sSDNA, coated by RPA. ATR-interacting protein (ATRIP) recognises RPA-coated ssDNA and recruits ATR. Once ATR signalling is activated, it leads to G2/M checkpoint activation and stabilisation of stalled replication forks. Inhibition of ATR (here by VE822) can result in DSBs accumulation, due to collapsed replication forks, activation of ATM signalling, and cell death.

$327 \times 253 \mathrm{~mm}(168 \times 168 \mathrm{DPI})$ 